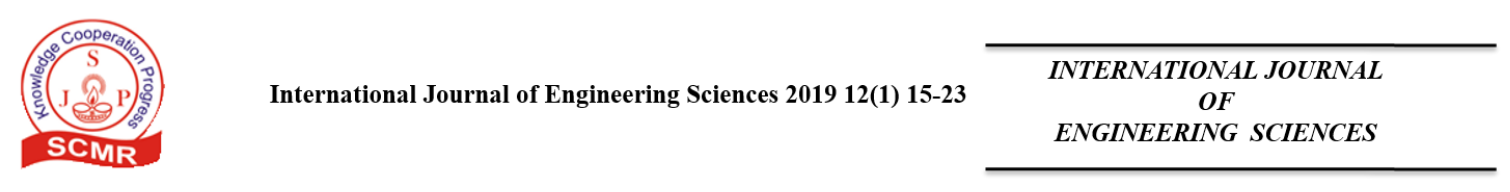

\title{
Fire Proof Quality of Metal Structures: A case study at the Algerian Complex Ourhoud
}

\author{
Marref Souad*, John Damascene A. Abeysekera ${ }^{\$}$ \\ *Institut d'Hygiène et Sécurité Université de Batna, Algérie \\ ${ }^{\$}$ WorkScience Academy, Swedene / Sri Lanka \\ (Received 7 October 2018; accepted 2 March 2019) \\ https://doi.org/10.36224/ijes.120103
}

\begin{abstract}
This article reflects an investigation into the use of passive protection against the fire based on the concept of fireproofing. The use of this technique obeys to international standards especially the 2218 API used as reference in order to achieve the purposes of this approach; Indeed the present study attests to the methodology of the fireproofing used at the complex "Ourhoud" and to the identified discrepancies at some of its installations and this in comparison to the recommendations of the standard and the requirements of the safety philosophy of this project.
\end{abstract}

Keywords: Risk management, fire explosions risk, fireproofing, the 2218 API, the petroleum industry, the Algerian industry

\section{Introduction}

The Industrial and technological development continues to generate several types of potential risks from different origins, such as pressure risk, electrical risk, fire risk and explosion.

The hydrocarbons industry, like many others, is not spared from these risks, sometimes catastrophic as regards their combination, including fire and explosion. The presence of products used in such units, which are highly flammable, combined with combustion can cause explosions and fires of colossal size.

To avoid these events, particularly dangerous for people and property, there are certain techniques already ancient that have achieved a certain level of security, but it is still possible to improve this safety through the use of new technologies such as the investigation on the use of passive protection against the fire and which is commonly known as the fireproofing.

To recall this technique is essential in the hydrocarbon sector and its use is governed by international standards especially the 2218 API used as a reference to elaborate this work.

This is a research study on quality of the product of the fireproofing used at the level of this complex and for which we managed with the help of the officials of the HSE department to identify discrepancies in some installations and compare the recommendations with the standard and the requirements of the safety philosophy of this project.

\section{Technique for protecting the facilities by the method of fireproofing}

\subsection{The Function of the fireproofing}

The equipment design, the location and the spacing are of great importance, they contribute in a substantial way to limiting the effects of a probable fire that could occur accidentally. 
The other way involved in limiting the damage caused by the fire is the application of a passive protection (PFP protection by Fire proof) called fireproofing, as opposed to the active protection provided by mobile devices such as monitors and fire fighting networks.

This coverage protects operating systems when exposed to fire.The primary role of the fireproofing occurs at the beginning of the incident to ensure the thermal isolation of the equipment, time to allow the closure of the unit, the isolation of the flow fuel on fire, the switching on of the fire-fighting equipment.

The installations to fight against the fire such as fixed water spray systems, the monitors, the fire-fighting trucks or the mobile pipe lines also provide an active protection but may, if the fire is very severe, not be able to quench it.

In the absence of the fireproofing, and at the beginning of the fire, the steel supports and under the effect of heat flux, lose their characteristics and may collapse even before the release of the above mentioned actions.

The implementation of a fireproofing protection can help to substantially reduce human and material losses and gives the time needed to the intervention team to respond with the adequate anti fire action.

The role of the fireproofing therefore is limited to ensuring the following three actions:

- The stability of the characteristics of the steel, particularly its resistance to breaking

- Flame resistance

- Thermal isolation

\section{Critical study of the materials to isolate (Petroleum centenarians "pipeline")}

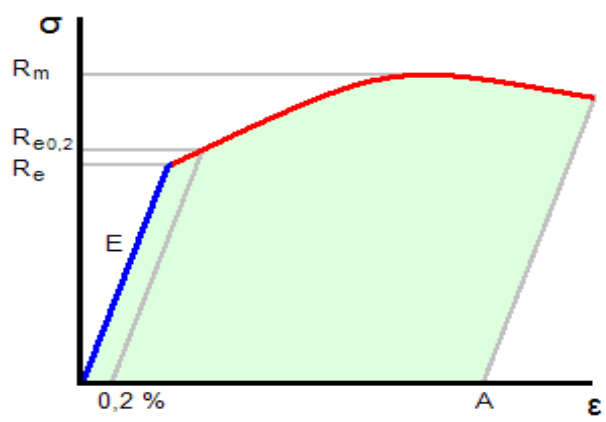

Figure 1: Diagram of the deformation curve of a steel

Rm: breaking constraint

Re: elastic limit real

Re 0,2 corresponding to a plastic elongation of $0.2 \%$

A: elongation in $\%$ of the specimen

\subsection{Reaction of steel in front of a fire}

The reaction of structures exposed to fire depends on the speed at which these elements are heated and the temperature distribution into the sections and length of the elements. The mechanical properties of the materials decrease with the increasing temperature and, consequently, the mechanical strength of the elements and therefore the structure also decreases. The collapse occurs when the resistance is equal to the action of the applied loads. This can happen in a very short time when the rise in temperature is rapid. In this regard, the unprotected metallic elements present, in some situations, cause an 
unfavourable reaction due to the very high conductivity of the steel. In comparison, a mixed elements or protected by isolating system have a better performance, because the thermal inertia of the elements is more significant and the thermal conductivity of the isolating material is lower.

For bare steel, studies have determined that:

- At $500^{\circ} \mathrm{C}$ the resistance of iron is halved

- At $700{ }^{\circ} \mathrm{C}$ is reduced by one third

- At $800^{\circ} \mathrm{C}$ it is zero, the iron bends under its own weight

Classic tests on tensile specimen allowed illustrating the reaction of the steel, that is to say the variation of the stress according to the temperature variation (Figure 1).

The graph below (Figure 2) shows the loss of the mechanical characteristics of steel in the presence of a fire:

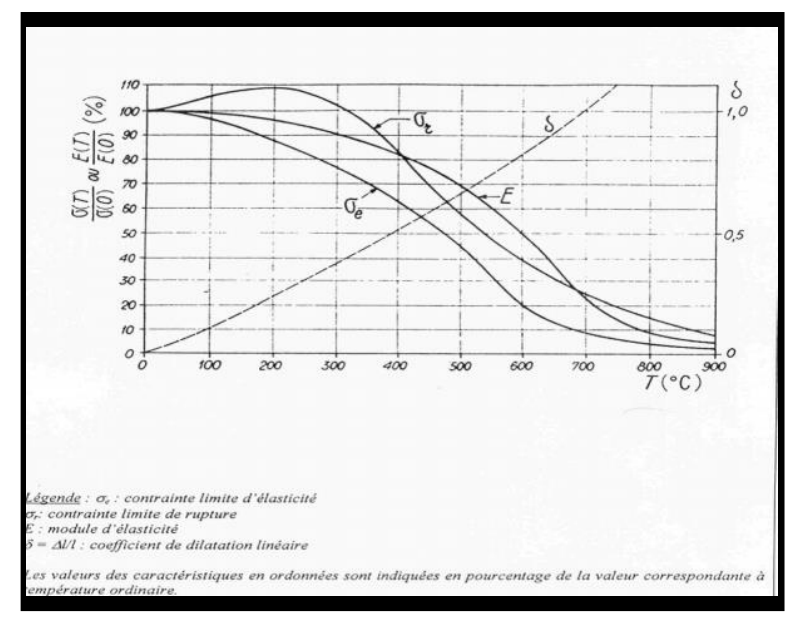

Figure 2: Mechanical properties of a common construction steel according to the temperature on tensile specimen (extracted graph of "the Engineer techniques")

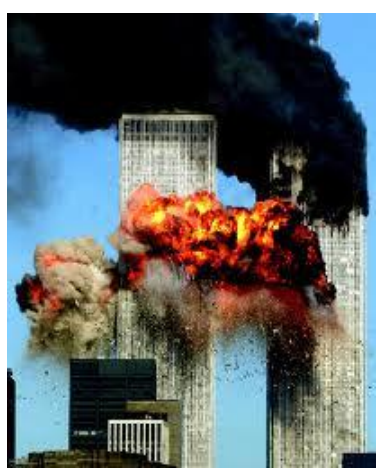

Figure 3: The twin towers on fire

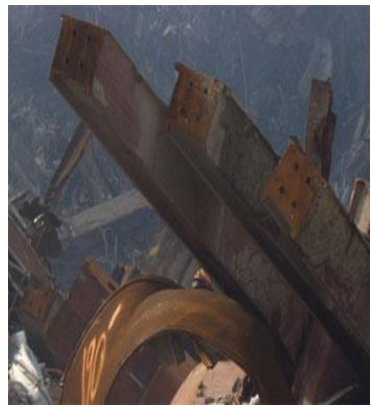

Figure 4: Steel with fireproof

\subsection{The process of heat transfer}

\subsubsection{The fire resistance of the fireproofing}

The use of the fireproofing in the industry and in other fields of activities including construction has become a means of protection against the inevitable fire. For example the pictures of the twin towers of the World Trade Centre (WTC) in New York, struck and collapsed on September 11, 2001 (Figure 3) and (Figure 4) will remain etched in everyone's memory. After more than three years of investigation who has 
accessed the analysis of 200 metal parts, the "National Institute of Standards and Technology (NIST)" concluded that:

The steel columns supporting the two towers have been weakened by the failure of fireproof coatings and consequently If the fire isolation had resisted [to the airplane impacts], fires would not have weakened the main elements of the constructions which eventually collapsed.

\subsection{Evaluation method of the resistance to fire}

During a fire, the temperature of the steel increases in the same way that the hot gas temperature but with a time lag. This time lag depends on the thermal inertia of the element. If the element is protected (fire resistant), the time lag is more important $(\mathbf{8 t}+\mathbf{1})$.

The evaluation methods of the resistance to fire of a metal already fire proofed refer to the fire exposure conditions and to the performance criteria set by the ISO 834 standard. The exposure of the element to fire is conducted according to the conventional thermal program represented by the function (Figure 5): $\mathrm{T}=345-\mathrm{To} \log 10(8 \mathrm{t}+1)$.

Where $\mathrm{t}=$ time [min]

$\mathrm{T}=$ temperature at the instant $\mathrm{t}\left[{ }^{\circ} \mathrm{C}\right]$

To $=$ Ambient temperature at the instant $\mathrm{t}=0 \min \left[{ }^{\circ} \mathrm{C}\right]$

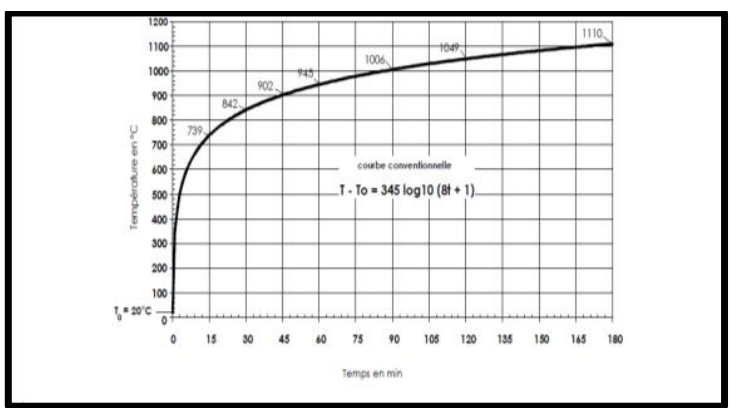

Figure 5: Graphical Evaluation of the resistance to fire of a metal

The performance of resistance to fire is expressed in degrees directly associated to the times in which the item satisfies the role assigned to it. Three levels of resistance to fire are then defined:

- Stability to fire: Only a criterion of resistance is required (carrier structural elements in general).

- Flame arrestors: In addition to the performance of structural fire, the element must satisfy the leakage criteria to flames and to hot or flammable gases.

- Fire-stop: In addition to the Flame arrestors performance, the element must satisfy criteria of thermal isolation.

The degrees of resistance to fire are: $1 / 4 \mathrm{~h}-1 / 2 \mathrm{~h}-3 / 4 \mathrm{~h}-1 \mathrm{~h}-1 \mathrm{~h} 1 / 2-2 \mathrm{~h}-3 \mathrm{~h}-$ $4 \mathrm{~h}-6 \mathrm{~h}$.

The ranking imposed on the fireproofing systems are based on the performance requirements of the crossed walls.

The different systems of fireproofing available on the market can certify performances ranging from a protection of $1 / 2 \mathrm{~h}$ to $3 \mathrm{~h}$. 


\subsection{Case Study of the complex "Ourhoud"}

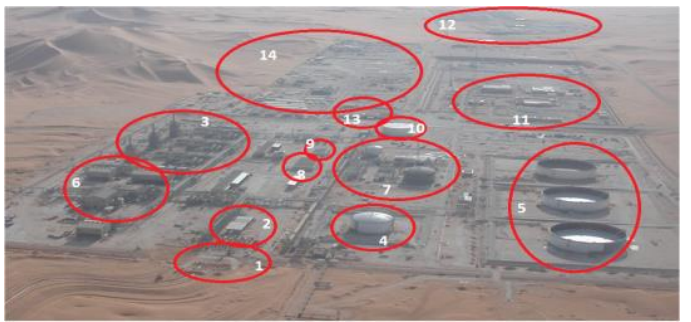

Figure 6: Succinct presentation of the production installations: General View of the CPF

For our installation (Figure 6) where the exposure time to fire determined by the hazard study is of two hours, the fireproofing product must be able to withstand a fed fire during the time determined by the formula $\mathrm{T}=345-\mathrm{t} 0$ fire $\log 10(8 \mathrm{t}+1)$.

Under the conditions in southern Algeria, T0 must be equal to $55^{\circ} \mathrm{C}$, value adopted by Sonatrach for the equipment size (Figure 7).

$\mathrm{t}=2 \times 60$ minutes $=120$ minutes

$\mathrm{T}=345 \log 10(8 \mathrm{X} 120+1)$

$\mathrm{T}=1049^{\circ} \mathrm{C}$

N.B: This value $\left(1049^{\circ} \mathrm{C}\right)$ is approximately that of the heat flux required by the 2218 standard and that should expose the fireproofing product chosen during performance tests.

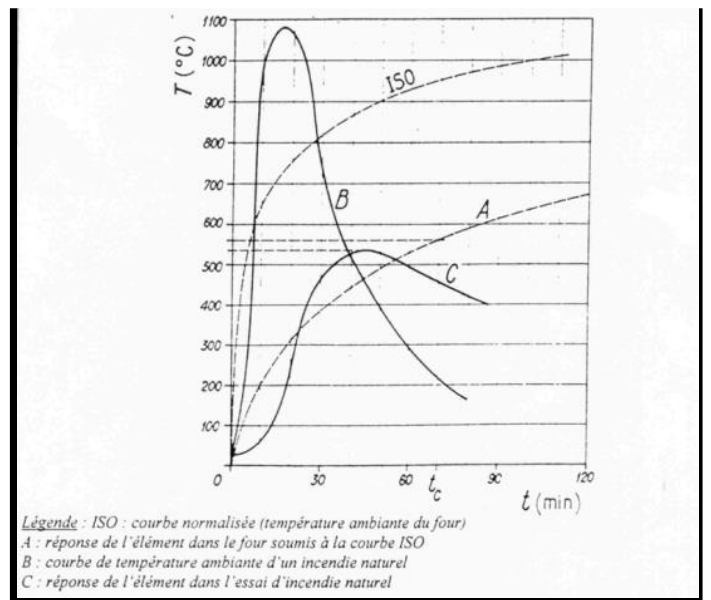

Figure 7: Evolution of temperatures (extracted graph of "the Engineer techniques ")

\section{Determining the Need in fireproofing}

The identification of needs in fireproofing is expressed for an oil or petrochemical plant based on a risk assessment which includes the occurrence of fire scenarios from which the needs analysis evolves.

An approach for the selection of the fireproofing system includes the following elements:

\subsection{Hazard assessment}

This assessment is made by processes such as the HAZOP, the What if, the QRA, etc. This step enables the needs assessment in fireproofing, the identification of the locations and the types of areas at risk of fire. The factors considered include the quantities, the pressures, temperatures and the chemical composition of the potential sources of fuel. 
- Equipment for High Potential Fire

- Equipment for Medium Potential Fire

- Equipment for Low Potential Fire

\subsection{Defining the development scenario of fire (Fire-Scenario Envelope)}

This part can be developed either by an experience feedback or by analyzing the possible accidents that may occur, it consists in identifying potential release rates and the size of the fire.

\subsection{Defining the fire scenario envelope}

For this point it is necessary to know the location of the equipment that may be affected in the presence of a likely fire, the nature of the product, the size and the potential scope of the fire.

The Fire-Scenario Envelope is the three-dimensional space in which the equipment has a potential of fire which may release flammable or combustible liquids forming a sheet of fire which can burn quite a long time and with sufficient intensity to cause substantial property damage. The definition of this scenario is based on the nature and the severity of the potential fires within the envelope.

The nature of this severity is the basis for determining the extent of the passive fireproofing and therefore determining the type and the degree of resistance to fire of the fireproofed materials.

The dimensions of Fire-Scenario Envelope can be based on the design rules based on the experiences or the qualitative or quantitative assessments.

For the liquid hydrocarbon fuels, and through the experience feedback, the protected area used frequently for the Fire-Scenario Envelope is that which extends from 20 to 40 feet (6 to 12 meters) horizontally and from 20 to 40 feet (6 to 12 meters) vertically from the source of liquid fuel.

\subsection{The needs for the performance of the analysis}

Classification of probable scenarios, are likely duration of the fire, the importance of heat flux, the vulnerability of the installation or the equipment.

\subsection{Selection of the chosen system}

This choice is made on the basis of the conditions provided by the standards relating to the equipment or the installation, the specific conditions of the supplier of the equipment and their level of protection and the experience feedback for the same type of equipment or installation 2218 standard rated (feedback) all facilities within their vulnerability and for which the support of the fireproofing is identified by determining the areas to be protected. 
4.6. Fireproofing in process areas (treatment areas) (Figure 8) and (Figure 9)

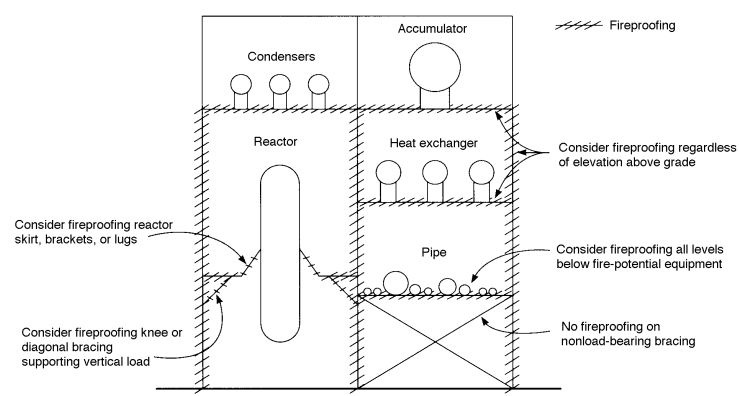

Figure 8: Support Structure fire -potential equipment and no fire-potential equipment, in an area of Scenario of fire

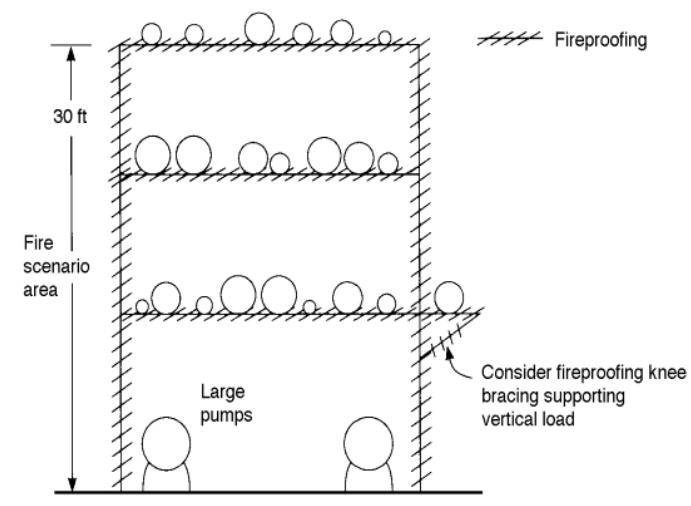

Figure 9: Pipe rack with large pumps potential fire installed below

\subsection{Audit of existing installations:}

During our training and the time allocated to us, we have carried out the verification of the conformity of the application of the product of the fireproofing of certain installations that are in operation and are subject to the requirements of the standard relating to fireproofing.

It should be noted that the equipment in question are those called into causes by the insurers and for which they reported that there was a need to review compliance. The audit focused on the following equipment:

a- air coolers:

What the standard provide:

This type of equipment which is designed to contain liquid hydrocarbons and which is consistent with Figure 6 of the standard must be protected by a fireproofing product.

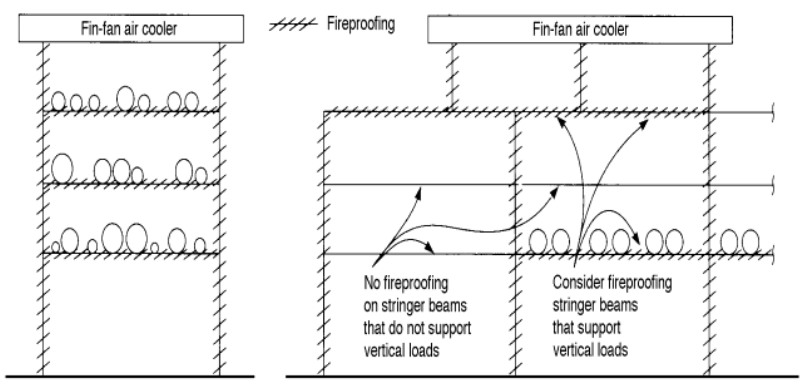

A1.Comment of Figure 10:

Figure 10: Air coolers 
It is found that this equipment is protected up to a height of 4.5 meters. In the safety philosophy adopted by the manufacturer, this height was chosen but it is not conform with the standard.

Due to the highly flammable liquid product conveyed by the air coolers and the fact that it can spread in all directions, this protection is not complete and as such there should be a horizontal protection 6 to 12 meters and an application for protection throughout the vertical support and according to Table 1 of the 2218 standard (6.1.2.2 and 6.1.3) and Figure 10 above.

The absence of such compliance in the event of fire may collapse the whole structure supporting these air coolers.

b. Racks of support for piping

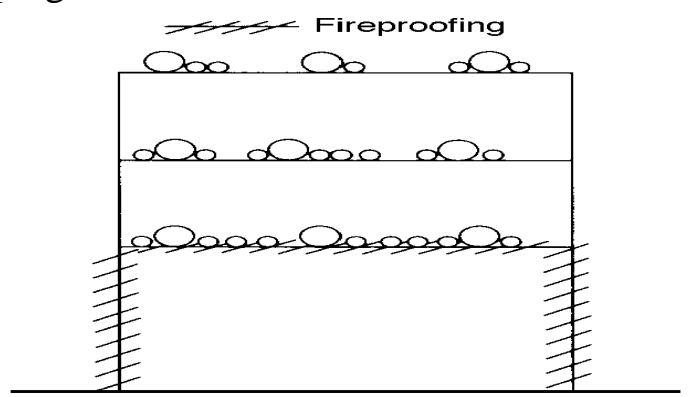

Figure 11: Pipe rack without pumps in a danger zone

The 2218 standard provides for this kind of facilities located in the zone of a fire influence a protection according to the case:

The protection is performed on a horizontal stretch of 6 to 12 meters and vertically to the first level of piping and specifically 15 meters for racks located around balloons containing LPG (liquefied Propane Gas) and this because of its highly flammable nature. If the last level of the pipes racks contains pipes with diameters of more than 6 meters, it must be fireproofed to this level or up to 9 meters high. The summary of the audit is presented as follows:

It is clear that the racks are fireproofed up to a height of 4.5 meters and that the horizontal beams are not even protected although they are in an area that has a high potential for fire and that in these cases the standard has clearly recommended its protection according to the principle retained of the fire scenario.

This method of protection that has been retained by the adopted safety philosophy does not conform with the recommendations of the 2218 standard.

Indeed and as it was found, the protection of the pipes racks is provided by the applicable standard and consequently Sonatrach must support this gap in comparison to that standard.

\section{Conclusion}

The opportunity that was given to us to share with Sonatrach the concern to support the issue of conformity of the fireproofing was very beneficial for us. Indeed, this study has allowed us to become familiar with such installations that deal with a very sensitive area: the security of installations.

In auditing, it was confirmed that the HSE Department of Sonatrach will hold an action of control and a thorough check on all metal structures supporting equipment 
containing combustible liquids, the ESDV and the wiring control of the safety valves located inside the Fire Scenario Envelope.

This audit will make it possible to determine the gaps with the standard (API 2218) and to determine the equipment to be fireproofed.

Acknowledgment: We thank all Sonatrch executives, including Mr. Meziane Mohamed and Aisha Mohamed respectively Ourhoud Unit Director And Head of Department Health, Safety and Environment and for their availability and their support throughout this work.

\section{References}

1. Birnbaum, Linda S. and Daniele F. Staskal, Brominated Flame Retardants: Cause for Concern?, Environmental Health Perspectives, 2003, 112(1), 9 (PMID 14698924, PMCID 1241790, DOI 10.1289/ehp.6559)

2. Kyle D'Silva, Alwyn Fernandes and Martin Rose, Brominated Organic MicropollutantsIgniting the Flame Retardant Issue, Critical Reviews in Environmental Science and Technology, 2004, 34(2), 141-207 (DOI 10.1080/10643380490430672)

3. Robin J. Law, Martin Kohler, Norbert V. Heeb, Andreas C. Gerecke, Peter Schmid, Stefan Voorspoels, Adrian Covaci, Georg Becher et Karel Janak, Hexabromocyclododecane Challenges Scientists and Regulators, Environmental Science \& Technology, 2005, 39, 281A (DOI 10.1021/es053302f). (en) Cynthia A. de Wit, An overview of brominated flame retardants in the environment, Chemosphere, 2002, 46(5), 583-624 (DOI 10.1016/S0045-6535(01)00225-9)

4. Andrée Charles, Farid Baddache. Preventing risks. Acting as a responsible organization. AFNOR Editions; 2006. ISBN 2-1247-5519-6

5. European Environment Agency, Late Lessons from Early Warnings $n^{\circ} 2$; Environmental issue report, 2013, 750 